\title{
Functional Relation between $\delta$-Aminolevulinate Synthesis System and Succinyl-coenzyme A Synthesis System in Rat Liver Mitochondria*
}

\author{
Takeshi Yoshida $†$ and Nobuo Ishihara \\ Department of Biochemistry (Prof. G. Kikuchi), \\ Tohoku University School of Medicine, Sendai
}

\begin{abstract}
The level of succinyl-CoA synthetase in rat liver mitochondria was not appreciably increased by the administration of allylisopropylacetamide (AIA), while the activity of $\delta$-aminolevulinate synthetase in liver mitochondria was increased more than ten times in these rats. The synthesis of $\delta$-aminolevulinate by liver mitochondria was significantly increased by the addition of ATP in the assay system. The ATP-stimulated increase of the $\delta$-aminolevulinate synthesis in mitochondria from control rats was completely abolished by the further addition of atractyloside, but the ATP-stimulated synthesis of $\delta$-aminolevulinate by mitochondria from AIA-treated rats was far less sensitive to atractyloside. The atractyloside barrier itself appeared to be not affected by the AIA administration as far as examined with respect to the $a$-ketoglutarate oxidation system and the ATPase system.
\end{abstract}

In the chemically induced porphyria animals, the activity of $\delta$-aminolevulinate synthetase in liver mitochondria is greatly increased. ${ }^{1-6}$ The substrates of $\delta$-aminolevulinate synthesis are succinyl-CoA and glycine $e^{7,8}$ and the production of succinyl-CoA in liver mitochondria depends upon the function of succinyl-CoA synthetase. Thus, it is expected that if some significant change occurs in the succinyl-CoA synthesis system, it would exert a significant influence upon the activity of $\delta$-aminolevulinate synthesis. In fact, it was shown that the yield of $\delta$-aminolevulinate by liver mitochondria from normal rats was increased by more than $60 \%$ when malonate was further added to the incubation mixture which contained $a$-ketoglutarate and glycine as substrates. ${ }^{2}$ Further, it was reported by Labbe et al..$^{9}$ that the total activity of succinyl-CoA synthetase in liver mitochondria from AIA-induced porphyria mouse was increased by about $70 \%$ and the inducible fraction of the enzyme was the isozyme of the non-inducible constitutive enzyme.

Considering these circumstances, we investigated in more detail the role of succinyl-CoA synthesis system in the $\delta$-aminolevulinate synthesis in rat liver mitochondria. A part of this work was reported in a preliminary form. ${ }^{10}$

Received for publication, May 8, 1969.

* This work formed part of thesis of T. Yoshida submitted to the Tohoku University for the partial fulfillment of the requirement for the degree of Doctor of Medical Science.

$\dagger$ Present Address: Department of Obstetrics and Gynecology, Tohoku University School of Medicine, Sendai. 


\section{Materials and Methods}

Conditioning of rats. Male rats of Wistar strain, weighing 150 to $200 \mathrm{~g}$, were fasted for 24 hours unless otherwise stated, after which $25 \mathrm{mg}$ AIA per $100 \mathrm{~g}$ body weight were injected subcutaneously at 12 hour intervals. Rats were maintained fasting throughout the experiments.

Enzyme preparations. Suspensions of rat-liver mitochondria were prepared in the same way as described by Narisawa and Kikuchi ${ }^{4} ; 1 \mathrm{ml}$ of the final suspension corresponded to $1 \mathrm{~g}$ of fresh liver and contained usually $20-25 \mathrm{mg}$ protein. Protein amounts were determined by a biuret method, employing the calibration curve standardized according to the Kjeldahl method.

The acetone powder of mitochondria was prepared by the method described by Morton. ${ }^{11}$ Enzyme extraction from the powder was performed by using $0.1 \mathrm{M}$ Tris- $\mathrm{HCl}$ buffer ( $\mathrm{pH} 7.4$ ); insoluble materials being precipitated off by $60 \mathrm{~min}$ centrifugation at $10,000 \times \mathrm{g}$.

Assay of enzyme activities. Reactions for the assay of $\delta$-aminolevulinate synthetase and succinyl-CoA synthetase activities were carried out in Erlenmeyer flasks of approximately $20 \mathrm{ml}$ capacity in a shaking water bath incubator. Compositions of the reaction mixtures for the assay of $\delta$-aminolevulinate synthetase are given in Table 2 . Reactions were terminated by adding trichloroacetic acid (final, 2.5\%). $\delta$-Aminolevulinic acid formed was estimated by the method described by Narisawa and Kikuchi. ${ }^{4}$ The color was developed by addition of Ehrlich's reagent and the millimolar extinction coefficient for $\delta$-aminolevulinic acid was assumed to be 53 at $553 \mathrm{~m} \mu$. The synthesis of $\delta$-aminolevulinic acid proceeded linearly for about $40 \mathrm{~min}$, the rate then gradually declining, so that enzyme activities were estimated by employing values obtained at $30 \mathrm{~min}$ of incubation.

Succinyl-CoA synthetase activity was assayed according to the method of Kaufman. ${ }^{12}$ Details of the assay conditions are described in respective tables and figures.

ATPase activity of intact mitochondria was estimated essentially by the method of Wojtczak and Zaluska ${ }^{13}$. Inorganic phosphate liberated was estimated by the method of Takahashi.14

Assay of ${ }^{14} \mathrm{CO}_{2}$. Reactions with ${ }^{14} \mathrm{C}$-labeled substrates were carried out in Warburg manometric flasks. ${ }^{14} \mathrm{CO}_{2}$ liberated was trapped into $0.2 \mathrm{ml}$ of $20 \% \mathrm{KOH}$ placed in the center well of the flask, and converted into $\mathrm{BaCO}_{3}$ by precipitation with $\mathrm{BaCl}_{2}$. Before addition of $\mathrm{BaCl}_{2}, 100 \mu$ moles of $\mathrm{Na}_{2} \mathrm{CO}_{3}$ were added as the carrier. Radioactivity was measured by a gas flow counter and expressed in terms of counts per min at infinite thinness. The counter employed counted approximately 10,000 c.p.m. per $\mu$ mole of ${ }^{14} \mathrm{C}$-sample of $0.01 \mathrm{mc} / \mathrm{mmole}$.

Reagents. AIA was kindly supplied from F. Hoffmann-La Roche \& Co., Basel. ADP, GTP, CoA and hexokinase (Type II) were obtained from Sigma Chem. Co., U.S.A.; pyridoxal phosphate, from Nutritional Biochem. Corp., U.S.A.; ATP, from Schwarz Biochemical Incorp., U.S.A.; citrate-1,5-14C and DL-glutamate-1-14 C, from Daiichi Chemical Co., Tokyo. $\alpha$-Ketoglutarate-1-14 $\mathrm{C}$ was prepared from glutamate-1. ${ }^{14} \mathrm{C}$ by the exchange transamination using crystalline glutamate-oxaloacetate transaminase obtained from Böhringer, Manheim. Atractyloside was a generous gift from Prof. T. Ajello, University of Palermo, Italy.

\section{Results}

Succinyl-CoA synthetase of rat-liver mitochondria. As shown in Table 1, succinyl-CoA synthetase activity of liver mitochondria from AIA-treated porphyria rats was not appreciably different from that from AIA-untreated control rats. A similar comparative study was made also with liver mitochondria from normal and porphyria mice, but again no significant activity difference could be observed between two mitochondrial preparations from AIA-treated and untreaed mice. In Fig. 1 are shown the relationships between $\mathrm{pH}$ and succinyl-CoA synthetase activities 
TABLE I. Succinyl-CoA synthetase activities in liver mitochondria from control rats and AIA-treated porphyria rats

\begin{tabular}{l|c}
\hline \multicolumn{1}{c|}{ Origin of mitochondria } & $\begin{array}{c}\text { Succinyl-CoA synthetase activity } \\
\text { (m } / \text { moles of hydroxamate/ } \\
\text { mg protein } / \mathrm{hr} \text { ) }\end{array}$ \\
\hline Control rats & $467(6)$ \\
Rats treated with AIA for $24 \mathrm{hr}$ & $\mathbf{4 4 0 ( 6 )}$ \\
Rats treated with AIA for $3 \mathrm{hr}$ & $482(4)$
\end{tabular}

Reaction mixtures contained, in a final volume of $2.0 \mathrm{ml}, 100 \mu$ moles of potassium succinate, $10 \mu$ moles of ATP, $0.12 \mu$ mole of $\mathrm{CoA}, 2.88$ mmoles of $\mathrm{NH}_{2} \mathrm{OH}$ adjusted to $\mathrm{pH}$ 7.4, $5 \mu$ moles of mercaptoethanol, $10 \mu$ moles of $\mathrm{MgCl}_{2}, 200 \mu$ moles of Tris-HCl buffer ( $\mathrm{pH}$ 7.4 ), and $0.3 \mathrm{ml}$ of respective mitochondrial suspensions. Reactions were carried out for 30 $\min$ at $37^{\circ}$. The values in the table are the averages of values obtained with the numbers of animals given in brackets.

* Rats were injected AIA ( $25 \mathrm{mg} / 100 \mathrm{~g}$ body weight) at 0 and $12 \mathrm{hr}$ and killed for enzyme assay at $24 \mathrm{hr}$ of the experiment. The mitochondrial preparations employed synthesized about 14 mumoles of $\delta$-aminolevulinate per $\mathrm{mg}$ protein per $\mathrm{hr}$, when assayed under conditions as described in Table 2.

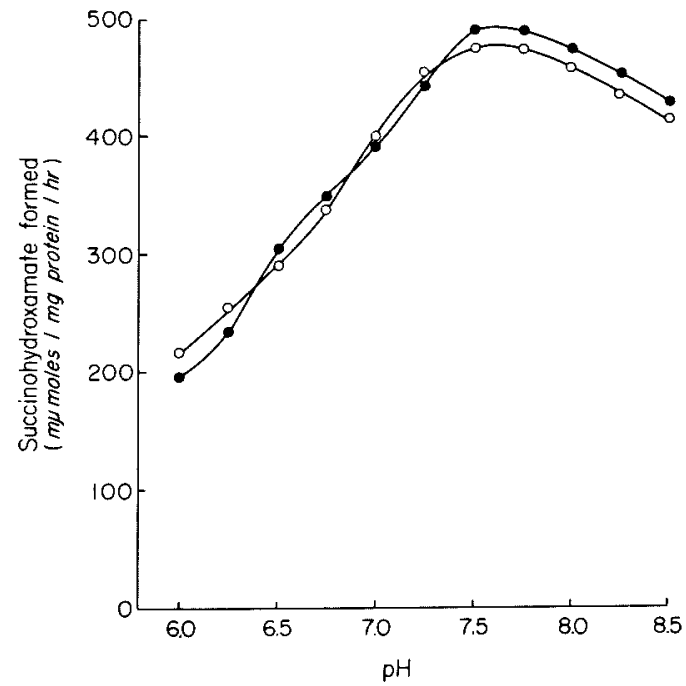

Fig. 1. Relationships between $\mathrm{pH}$ and succinyl-CoA synthetase activities of intact liver mitochondria from control and AIA-treated rats, respectively. Reaction conditions were similar to those in Table 1 , except that varied $\mathrm{pH}$ of hydroxylamine and 700 $\mu$ moles of Tris-maleate buffer were employed. The pH's indicated in the figure represent those of respective final reaction mixtures measured by a glass-electrode pH meter. Closed circle, control rats; open circle, AIA-treated rats.

of rat-liver mitochondria. The optimal $\mathrm{pH}$ was found to be about 7.7 with either mitochondrial preparations. Also the pattern of the $\mathrm{pH}$-activity curves did not appear to support the occurrence of two succinyl-CoA synthetases with different $\mathrm{pH}$ response in either mitochondrial preparations. In Fig. 2 are shown the results of similar experiments made with solubilized enzyme preparations 


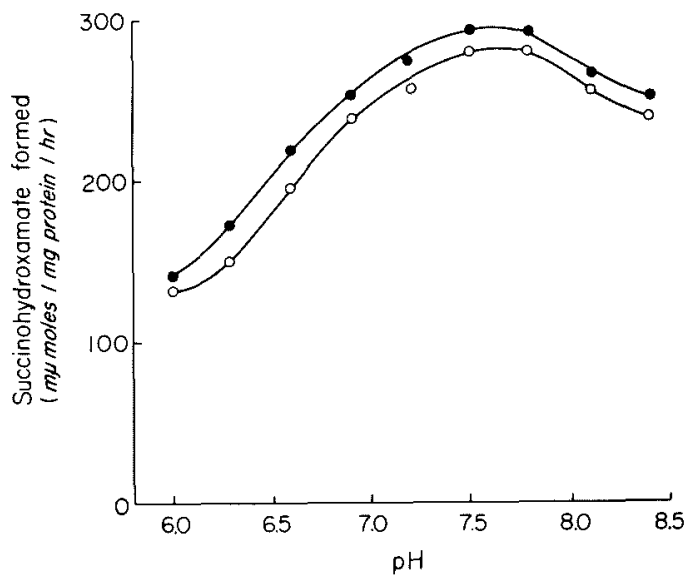

Fig. 2. Relationships between $\mathrm{pH}$ and succinyl-CoA synthetase activities of mitochondrial acetone powder extracts from control and AIA-treated rats. Reaction conditions were similar to those for Fig. 1, except that $500 \mu$ moles of Tris-maleate buffer were used and $1 \mu$ mole of GTP was added to each reaction mixture. Closed circle, control rats; open circle, ALA-treated rats.

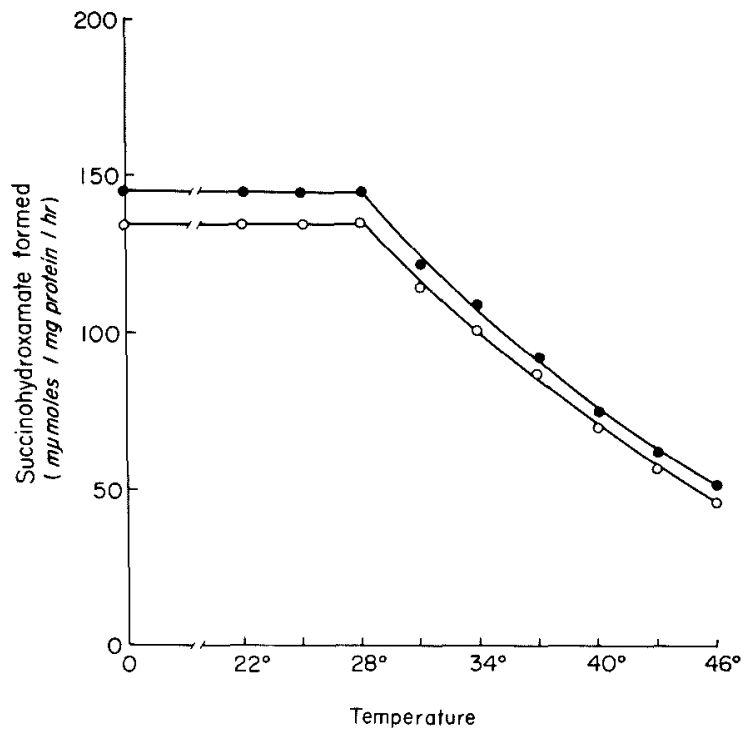

Fig. 3. Heat inactivation of succinyl-CoA synthetase in extracts of acetone powder of mitochondria from control and AIA-treated rats, respectively. $0.6 \mathrm{ml}$ of respective extracts was heated for $5 \mathrm{~min}$ at temperatures indicated in the figure, then added to the reaction mixture to start the reaction. Reactions for the enzyme assay were carried out for $30 \mathrm{~min}$ at $22^{\circ} \mathrm{C}$. Other conditions were similar to those in Table 1 , except that $1 \mu$ mole of GTP was added to each reaction mixture. Closed circle, control rats; open circle, AIA-treated rats. 
(extracts of acetone powder of liver mitochondria); the features of the $\mathrm{pH}$-activity relationship are quite similar to those observed with intact mitochondria. Furthermore, as can be seen from Fig. 3 which shows the heat inactivation of the enzyme activity, the relationships between temperatures and activities of succinyl-CoA synthetase in extracts of acetone powder of mitochondria from either control and AIA-treated rats were very similar for each other. All these results are in sharp contrast with those reported by Labbe et al..$^{9}$ for mouse and rather support the view that mitochondria contain only the single succinyl-CoA synthetase and the level of this enzyme is not appreciably increased by the administration of AIA.

Effects of additions of ATP and atractyloside on the 8 -aminolevulinate synthesis. Usually the synthesis of $\delta$-aminolevulinate with intact mitochondria is considerably increased by the addition of ATP, and the stimulation by ATP is more pronounced when mitochondria were preincubated for about $20 \mathrm{~min}$ at $20^{\circ} \mathrm{C}$, probably because the preincubation reduced the phosphorylation activity of mitochondria. As shown in Table 2 , the synthesis of $\delta$-aminolevulinate with the preincubated mitochondria was increased by 1.5-to 2-fold by the addition of ATP. The stimulatory effect of ATP, however, was counteracted by the addition of atractyloside, a specific inhibitor of translocation of adenine nucleotides across the inner membrane of mitochondria ${ }^{15}$ (Table 2). With mitochondria from control rats, the ATPstimulated increase of $\delta$-aminolevulinate synthetase was abolished nearly completely by atractyloside, indicating that atractyloside completely inhibited the translocation of exogenously added ATP across the atractyloside barrier in these

TABLE 2. Effects of addition of ATP and atractyloside on the $\delta$-aminolevulinate synthesis by liver mitochondria from control and $A I A$-treated rats

\begin{tabular}{|c|c|c|c|c|}
\hline Hours of & \multicolumn{3}{|c|}{$\begin{array}{l}\delta \text {-Aminolevulinate formed } \\
\text { (m } \mathrm{m} \text { moles } / \mathrm{mg} \text { protein } / \mathrm{hr} \text { ) }\end{array}$} & Rate of in- \\
\hline $\begin{array}{l}\text { AlA- } \\
\text { treatment }\end{array}$ & $\begin{array}{l}\text { Standard } \\
\text { system }\end{array}$ & $\begin{array}{l}\text { Standard } \\
\text { system plus } \\
\text { ATP }\end{array}$ & $\begin{array}{l}\text { Standard system } \\
\text { plus ATP and } \\
\text { atractyloside }\end{array}$ & $\begin{array}{l}\text { atractyloside } \\
(\%)^{*}\end{array}$ \\
\hline 0 & 0.9 & 1.5 & 0.9 & 100 \\
\hline 3 & 1.9 & 3.8 & 2.7 & 58 \\
\hline 6 & 2.6 & 4.4 & 3.3 & 67 \\
\hline 18 & 7.9 & 13.3 & 11.8 & 28 \\
\hline 36 & 7.7 & 13.2 & 12.0 & 22 \\
\hline
\end{tabular}

Rats were injected with AIA at 0,12 and $24 \mathrm{hr}$, and killed for the activity assay at the times indicated in the Table. Standard system contained, in a final volume of $2.0 \mathrm{ml}$, $100 \mu$ moles of potassium phosphate buffer of pH 7.4, $100 \mu$ moles of glycine, $10 \mu$ moles of succinate, $0.2 \mu$ mole of pyridoxal phosphate, $0.06 \mu$ mole of CoA, $5 \mu$ moles of mercaptoethanol, and about $10 \mathrm{mg}$ as protein of mitochondrial suspension. The mitochondrial preparations were preincubated for $20 \mathrm{~min}$ at $30^{\circ}$ before use. ATP and atractyloside added were $5 \mu \mathrm{moles}$ and $0.1 \mu$ mole, respectively. Reactions were carried out at $37^{\circ}$.

* Rates of inhibition ( $\%$ ) were calculated according to the following equation:

(Standard system + ATP) - (Standard system + ATP + atractyloside) $-\times 100$ (Standard system + ATP) - (Standard system) 
mitochondria. However, with mitochondria from AIA-treated rats which had much higher activities of $\delta$-aminolevulinate synthetase than those from control rats, the effect of atractyloside was less significant; when the mitochondria employed were those prepared from rats treated with AIA for $36 \mathrm{hr}$, the ATPsupported increment of $\delta$-aminolevulinate synthesis was reduced by only about $20 \%$ by the addition of atractyloside.

Effect of atractyloside on the ${ }^{14} \mathrm{CO}_{2}$ liberation from ${ }^{14} \mathrm{C}$-labeled substrates. With the aim to obtain further information concerning the observed difference in atractyloside sensitivity of $\delta$-aminolevulinate sunthesis system between mitochondria from control rats and AIA-treated rats, the effect of atractyloside on the $\alpha$-ketoglutarate oxidation system was examined using $\alpha$-ketoglutarate-1-14 $\mathrm{C}$ and citrate- $1,5^{-14} \mathrm{C}$ as the substrates. It is well known that the substrate level phosphorylation associated with the $a$-ketoglutarate oxidation is highly dependent upon the available ADP and Pi. As can be seen from Table 3, the mitochondrial

TABLE 3. Effects of addition of ADP-hexokinxse-glucose system and atractyloside on the ${ }^{14} \mathrm{CO}_{2}$ formation from a-ketoglutarate-1-14 $\mathrm{C}$ and citrate-1,5-14 $\mathrm{C}$ catalyzed by liver mitochondria

\begin{tabular}{|c|c|c|c|}
\hline \multirow[t]{2}{*}{ Substrate } & \multirow[t]{2}{*}{ Addition } & \multicolumn{2}{|c|}{$\begin{array}{c}{ }^{14} \mathrm{CO}_{2} \text { formed } \\
\text { (c.p.m./mg protein) }\end{array}$} \\
\hline & & Control rat & AIA-treated rat* \\
\hline a-Ketoglutarate- $1{ }^{14} \mathrm{C}$ & $\begin{array}{l}\text { None } \\
\text { ADP-H.G system } \dagger \\
\text { ADP-H-G system and } \\
\quad \text { atractyloside }\end{array}$ & $\begin{array}{l}2900 \\
8100 \\
2920\end{array}$ & $\begin{array}{l}2800 \\
8400 \\
3350\end{array}$ \\
\hline Citrate- $1,5-{ }^{14} \mathrm{C}$ & $\begin{array}{l}\text { None } \\
\text { ADP-H-G system } \\
\text { ADP-H-G system and } \\
\quad \text { atractyloside }\end{array}$ & $\begin{array}{l}255 \\
644 \\
251\end{array}$ & $\begin{array}{l}258 \\
620 \\
273\end{array}$ \\
\hline
\end{tabular}

Reaction mixtures contained, in a final volume of $2.8 \mathrm{ml}, 10 \mu$ moles of citrate-1,5-14 $\mathrm{C}$ or a-ketoglutarate-1.14 $\mathrm{C} \quad(0.01 \mathrm{mc} / \mathrm{mmole}), 5 \mu$ moles of $\mathrm{MgCl}_{2}$, $15 \mu$ moles of potassium phosphate buffer ( $\mathrm{pH} 7.2$ ), $120 \mu$ moles of Tris-HCl buffer (pH 7.2), $100 \mu$ moles of KCl, 200 $\mu$ moles of sucrose, $10 \mu$ moles of malonate, and appropriate amounts of mitochondria. ADP, hexokinase, glucose and atractyloside added were $5 \mu$ moles, $0.1 \mathrm{mg}, 30 \mu \mathrm{moles}$ and 0.1 $\mu$ mole, respectively. Reactions were carried out for $20 \mathrm{~min}$ at $30^{\circ}$ and terminated by addition of trichloroacetic acid.

Note: Liver mitochondria prepared from AIA-treated rats and employed in these experiments formed 12 to $13 \mu$ moles of $\delta$-aminolevulinate $/ \mathrm{mg}$ protein $/ \mathrm{hr}$, when assayed under the standard reaction conditions as described in Table 2 (but omitting the preincubation of mitochondrial suspensions).

* Rats were treated with AIA for $36 \mathrm{hr}$.

$\dagger \mathrm{H}$ and $\mathrm{G}$ stand for hexokinase and glucose, respectively.

preparations from either control rats or AIA-treated rats catalyzed the oxidation of $\alpha$-ketoglutarate at nearly the same rate as judged by the ${ }^{14} \mathrm{CO}_{2}$ formation from those ${ }^{14} \mathrm{C}$-labeled substrates. The activities in either mitochondrial preparations 
increased apparently to the same degree when the ADP-hexokinase-glucose system was added as a phosphate acceptor system, but when atractyloside was further added, the increase of $\alpha$-ketoglutarate oxidation resulted by the addition of the hexokinase system was completely abolished. These results clearly indicate that the atractyloside barrier is still intact even in mitochondria from AIA-treated rats as far as it is concerned with the $\alpha$-ketoglutarate oxidation system.

ATPase activity. As shown in Table 4, the 2,4-dinitrophenol-stimulated ATPase activity was completely blocked by atractyloside, indicating again the intactness of atractyloside barrier in both mitochondrial preparations.

TABLE 4. Effect of atractyloside on the 2,4-dinitrophenol-stimulated ATPase activity of liver mitochondria

\begin{tabular}{l|c|c}
\multicolumn{1}{c|}{ Addition } & \multicolumn{2}{|c}{$\begin{array}{c}\text { Pi liberated } \\
(\mu \text { moles per flask })\end{array}$} \\
\cline { 2 - 3 } & Control rat & AIA-treated rat ${ }^{*}$ \\
\hline None & 4.28 & 5.50 \\
Atractyloside $(0.1 \mu$ mole $)$ & 0.37 & 0.07
\end{tabular}

Reaction mixtures contained, in a final volume of $1.5 \mathrm{ml}, 112 \mu$ moles of KCl, $60 \mu$ moles of Tris-HCl buffer ( $\mathrm{pH} 7.6$ ), $1.5 \mu$ moles of $\mathrm{MgCl}_{2}, 0.1 \mathrm{mM}$ of 2,4-dinitrophenol, $5.0 \mu$ moles of ATP, and $2.3 \mathrm{mg}$ as protein of respective liver mitochondria. Reactions were carried out for $15 \mathrm{~min}$ at $22^{\circ}$.

Note: Liver mitochondria prepared from control rats and AIA-treated rats and employed in these experiments gave 1.5 and $12.4 \mathrm{~m} \mu$ moles of $\delta$-aminolevulinate $/ \mathrm{mg}$ protein $/ \mathrm{hr}$, respectively, when assayed under the standard reaction conditions as described in

Table 2 (but omitting the preincubation of mitochondrial suspensions).

* Rats were treated with AIA for $36 \mathrm{hr}$.

\section{Discussion}

In the present investigation, no evidence could be obtained for the occurrence of isozymes of succinyl-CoA synthetase in liver mitochondria. Moreover, the succinyl-CoA synthetase activity in liver mitochondria did not appreciably increase when animals were treated with AIA. It may be assumed that liver mitochondria contain only the single succinyl-CoA synthetase and this enzyme is not inducible by the administration of AIA.

It is noteworthy that the ATP-stimulated increase of $\delta$-aminolevulinate synthesis in mitochondria from AIA-treated rats was relatively insensitive to atractyloside, while the ATP-supported increase of the $\delta$-aminolevulinate synthesis in mitochondria from control rats was completely abolished by atractyloside. The observed atractyloside insensitivity does not appear to be due to the breakage of atractyloside barrier in general in AIA-treated rats, because it was shown by the experiments with ${ }^{14} \mathrm{C}$-labeled substrates and also by the results of ATPase activity assay that the atractyloside barrier was not affected by the AIA administration. Thus the attitude of $\delta$-aminolevulinate synthesis system toward atractyloside in AIA-treated rats is quite unusual. Further studies are required to account for the problem in question. 


\section{Acknowledgment}

We are indebted to Prof. Ajello for kindly supplying atractyloside. This work was supported in port by U.S. PHS grant AM08016 (G. Kikuchi).

\section{References}

1) Granick, S. \& Urata, G. Increase in activity of $\delta$-aminolevulinic acid synthetase in liver mitochondria induced by feeding of 3,5-dicarbethoxy-1,4-dihydrocollidine. J. biol. Chem., 1963, 238, 821-827.

2) Miyakoshi, T. \& Kikuchi, G. Studies on experimental porphyria. Report I. Increased synthesis of $\delta$-aminolevulinic acid in allylispropylacetamide-induced porphyria rat. Tohoku J. exp. Med., 1963, 79, 199-208.

3) Tschudy, D.P., Welland, F.H., Collins, A. \& Hunter, G. Jr. The effect of carbohydrate feeding on the induction of $\delta$-aminoleuvlinic acid synthetase. Metabolism, 1964, 13, $396-406$.

4) Narisawa, F. \& Kikuchi, G. Mechanism of allylisopropylacetamide-induced increase of $\delta$-aminolevulinate synthetase in rat liver mitochondria. Biochim. biophys. Acta, $1966,123,596-605$.

5) Marver, H.S., Tschudy, D.P., Perlroth, M.G. \& Collins, A. $\delta$-Aminolevulinic acid synthetase. I. Studies in liver homogenates. J. biol. Chem., 1966, 241, 2803-2809.

6) Marver, H.S., Collins, A., Tschudy, D.P. \& Reichgl, Jr. $\delta$-Aminolevulinic acid synthetase. II. Induction in rat liver. J. biol. Chem., 1966, 241, 4323-4329.

7) Kikuchi, G., Kumar, A., Talmage, P. \& Shemin, D. The enzymatic synthesis of $\delta$ aminolevulinic acid. J. biol. Chem., 1958, 233, 1214-1219.

8) Laver, W.G., Neuberger, A. \& Udenfriend, S. Initial stages in the biosynthesis of prophyrins. I. The formation of $\delta$-aminolaevulic acid by particles obtained from chicken erythrocytes. Biochem. J., 1958, 70, 4-14.

9) Labbe, R.F., Kurumada, T. \& Onisawa, J. The role of succinyl-CoA synthetase in the control of heme biosynthesis. Biochim. biophys. Acta, 1965, 111, 403-415.

10) Yoshida, T., Ishihara, N. \& Kikuchi, G. On the relationship between $\delta$-aminolevulinate synthetase and succinyl-CoA synthesis system in rat liver mitochondria. Seikagaku (Jap.), 1966, 38, 907.

11) Morton, R.K. Methods of extraction of enzymes from animal tissues. In: Methods in Enzymology, Vol. I, ed. by S.P. Colowick \& N.O. Kaplan, Academic Press, New York, 1955, pp. 25-51.

12) Kaufman, S. P enzyme. In: Methods in Enzymology, Vol. I, ed. by S.P. Colowick \& N.O. Kaplan, Academic Press, New York, 1955, p. 718-722.

13) Wojtczak, L. \& Zaluska, H. The inhibition of translcoation of adenine nucleotides through mitochondrial membranes by oleate. Biochem. biophys. Res. Commun., 1967, 28, 76-81.

14) Takahashi, Y. Methods of determination of true inorganic phosphate value and creatine phosphate in tissue and on the actions of phosphoamidase and creatine phosphokinase in pig sperm. Seikagaku (Jap.), 1955, 26, 690-691.

15) Bruni, A., Luciani, S. \& Contessa, A.R. Inhibition by atractyloside of the binding of adenine-nucleotides to rat liver mitochondria. Nature, 1964, 201, 1219-1220. 